\title{
Contributors to Articles in Volume 22
}

\author{
Abdel-Ghany, M. 43 \\ Adams, F.G. 231 \\ Bean, F.D. 1 \\ Chen, Y. 231 \\ Cohen, S.B. 161 \\ Corder, L.S. 141 \\ Ferraro, D.L. 103 \\ Fleming, M. 89, 201 \\ Galvez, J. 25 \\ Ganti, S. 219 \\ Glick, J.E. 1 \\ Hogan, T.D. 129 \\ Howrey, E.P. 181 \\ Hwang, J.C. 57 \\ Jordan, J.S. $\quad 89,201$ \\ Lang, K.M. 89, 201 \\ Manton, K.G. 141 \\ McLarty, C. 25 \\ Paulin, G.D. 103 \\ Potter, D.E.B. 161 \\ Renfro, C.G. 241 \\ Sharpe, D.L. 43 \\ Steinnes, D.N. 129 \\ Van Hook, J.V.W. 1
}

